Inesa Toska, PhD Candidate, Faculty of Foreign Languages University of Tirana E-mail: inesatoska@gmail.com

\title{
TEACHING LEGAL ENGLISH IN MULTILEVEL CLASSES
}

\begin{abstract}
Legal English is a highly specialized language. Many words have another meaning in General English and another specific meaning in the legal field. In Albania students are aware of the importance of Legal English. Legal English teachers face many difficulties in teaching English for Specific Purposes. In multilevel classes these difficulties become even more prominent. What are some of the problems that teachers encounter in these classes? Why is Legal English so difficult to be taught? Why is it even more difficult when teachers deal with students of different levels? Can students with limited knowledge in English acquire Legal English? Can working in pairs help students improve language acquisition? Can students help each other by interacting actively and by having a positive attitude towards students of lower levels? What are some of the characteristics of Legal English? Can continuous qualifications and trainings help teachers overcome these problems? Can team teaching with a specialist in the legal field help the Legal English teachers?
\end{abstract}

Keywords: Legal English, Multilevel Classes, English for Specific Purposes, Legal English Teachers.

\section{Introduction}

This article will provide an overview focused on teaching Legal English in multilevel classes. The acquisition of English for Specific Purposes has become a necessity nowadays. Many people are eager to become successful in different fields. In order to achieve this, they need to be specialized in their fields. English has become a key component in helping them achieve professional and career development. Possessing good knowledge in General English isn't enough for ambitious people and students. The need of being good at English for Specific Purposes has become more prominent than ever before. In Albanian universities, English for Specific Purposes is a compulsory subject. Students have to attend the classes, be active, participate in different debates, deal with different assignments etc. In these classes students are given the opportunity to master their knowledge in English for Specific Purposes. Students in the Faculty of Law study Legal English. In this faculty students are aware of the importance of Legal English. They are aware of the fact that they need to work hard to acquire specific terminology and that the process of learning this specific language requires time, hard work, practice and persistence as well. Most students who attend this faculty dream of becoming successful lawyers, judges or prosecutors. The vision they have for their future encourages them to study hard despite the difficulties they encounter. The greater is the knowledge that they have in Legal English, the greater will be the chances to get the job they dream of.

Law students face many challenges during the learning process of Legal English. The first challenge is related to understanding the content of the subject and expressing this understanding in a manner accepted by the teacher (Saleh Qasim Al-Badwawi, $[12,54])$. This task can be very challenging for students with limited knowledge in General English. They make grammatical or spelling mistakes and in most of the cases they lack vocabulary to express their ideas. Students face many words which are unknown to them. They don't have knowledge regarding legalese which are terms of art used in legal 
profession, that are not known by people who are specialized in other professions.

\section{What makes Legal English so difficult?}

One of the main reasons why legal language is sometimes difficult to understand is because it is very different from ordinary English. According to Rupert Haigh this comprises two issues (Haigh, [10, 3]):

1. Sentences often have peculiar structures, punctuation is used insufficiently, foreign phrases are sometimes used instead of English phrases, unusual pronouns are employed (for example the aforesaid) and unusual set of phrases are to be found (null and void).

2. A large number of difficult words and phrases are used. These fall into four categories:

A. Legal terms of art- Legal terms of art are technical words and phrases that have precise and fixed meanings and which cannot usually be replaced by other words. These terms of art in the legal profession are known as legalese. They are appropriate when communicating with people in the field. If a reader is trained in law, using legal terms or phrases is much easier than providing a definition or explanation (Put$\operatorname{man}[11]$ ). When the recipient is not a lawyer, the use of these terms should be avoided. These terms must be defined when communicating with non-lawyers if the meaning of the term is not obvious.
For example: "The constitution requires probable cause before the police can conduct a search of your residence."

Revised:"The constitution requires the police to have a valid reason before they can search a house."

In this case the legalese "probable cause" can be substituted with "to have a valid reason". An example of a valid reason would be if a reliable person informed the police that they saw illegal drugs in the house.

B. Legal jargon- Legal jargon comprises words used by lawyers, which are difficult for non-lawyers to understand. It also includes certain obscure words which have highly specialized meanings and are therefore not often encountered in legal documents. They include a number of archaic words which are no longer used in ordinary English. Some of these are aforesaid, hereinbefore, hereinafter, henceforth, the said party (Putman [11]). It also includes some obscure words which have highly specialized meanings and are not encountered except for in legal documents. For example "emolument" refers to a person's earnings, including salaries, wages, fees, profits and benefits. These words should be replaced by Plain English whenever is possible (Haigh [10,3]).

Table 1.- Legal meaning may differ from the general meaning- Some words have one meaning as a legal term and another meaning in General English

\begin{tabular}{|l|l|l|}
\hline \multicolumn{1}{|c|}{ Word } & \multicolumn{1}{|c|}{ Legal meaning } & \multicolumn{1}{c|}{ General English meaning } \\
\hline $\begin{array}{l}\text { Consider- } \\
\text { ation }\end{array}$ & $\begin{array}{l}\text { Something of value that is given in return } \\
\text { for the promise (Delija \& Buza [13]) }\end{array}$ & $\begin{array}{l}\text { 1. Careful thought; } \\
\text { 2. A fact taken into account when making a } \\
\text { decision; } \\
\text { 3. Thoughtfulness towards others }\end{array}$ \\
\hline Sentence & $\begin{array}{l}\text { A punishment given to a person after } \\
\text { they have been found guilty of an offence } \\
\text { (Walenn, [2, 12]) }\end{array}$ & $\begin{array}{l}\text { A group of words with at least a subject and } \\
\text { a verb (Walenn, [2, 12]) }\end{array}$ \\
\hline Conviction & $\begin{array}{l}\text { A recording of guilt following a case } \\
\text { (Walenn, [2, 12]) }\end{array}$ & $\begin{array}{l}\text { Strong belief that something is true } \\
\text { (Walenn, [2, 12]) }\end{array}$ \\
\hline Case & $\begin{array}{l}\text { Legal arguments, facts and reasons, for or } \\
\text { against something; also, a previous legal } \\
\text { decision that influences subsequent deci- } \\
\text { sions (Walenn, [2, 12]) }\end{array}$ & $\begin{array}{l}\text { A bag that is used to carry clothes etc } \\
\text { (Walenn, [2, 12]) }\end{array}$ \\
\hline
\end{tabular}


C. Words may be used in peculiar contexts- A great number of words and phrases, which are used in General English, are also used in Legal English, but in unusual contexts. Such examples are the words furnish, hold, prefer.

According to David Mellinkoff Legal English lexis includes Latin, French and Anglo-Saxon words and phrases, rare words from Old English, professional jargon and formal expression reflected throughout contemporary usage and which makes it "a hard nut to crack" to modern learners (Mellinkoff [9, 11-29]). Words borrowed from Latin are Mens Rea, Habeas Corpus etc.

D. Lack of punctuation- Legal English is characterized by lack of punctuation. Punctuation is designed to make writing clear and easy to understand. Poor punctuation may cause the reader to misunderstand the context or be distracted by errors and not focus on the context. The current trend is inclined toward the emphasis of utility of punctuation due to the facilitating function that it plays in the sentences. Despite this tendency, punctuation still remains poor.

E. Doublets and triplets- The frequent use of "doublets and triplets" is noticed in Legal English. Another interesting fact is the use of two or three words together which express the same legal concept. Some examples are "null and void", "fit and proper", "care and attention", "perform and discharge", "terms and conditions", "dispute, controversy or claim”, "promise, agree and covenant" etc.

\section{Why is Legal English difficult to be taught?}

Teaching Legal English is a huge challenge for nonnative teachers who are not experts in law (Codruta $[4,832])$. Teachers may face problems when they have to teach content in an area of study about which they have little or no prior knowledge (Tavakoli, Nasri \& Rezazadeh [5]). The content may be very specific and require a high degree of knowledge from the teachers. The problem may be aggravated when the students' knowledge of the special subject is greater than the knowledge of their teacher. The solution proposed by John \& Dudley-Evans is team-teaching in which the ESP teacher collaborates with a subject specialist (John \& Dudley-Evans [6, 6-23]). In this case the Legal English teachers can collaborate with lawyers, judges, prosecutors or professors within the Law field. This kind of teaching proves to be very effective since the Legal English teachers are experts in language and the professors of Law are experts in the field of Law. The Law professors have knowledge regarding legal concepts and notions. They both can intertwine their knowledge and help the students understand and acquire knowledge in language and law at the same time. Hutchinson \& Waters believed that ESP teachers are not expected to become a teacher on the subject matter, but rather they should have a positive attitude towards the content knowledge of the basic principles of the subject matter and an awareness of their actual knowledge (Hutchinson \& Waters [7]). As Gonzales said about English teachers "as English teachers we are expert in language use and we have to emphasize this language in our classes" (Gonzales [8]). The teaching of Legal English as a second language raises two language related challenges. The first challenge has to do with the particularities and peculiarities of its vocabulary and sentence structure which are a great barrier to understanding Legal English. The second challenge focuses on the cultural differences between legal systems. There are some language skills and cultural particularities that can't be ignored especially when we deal with Legal English. Since law is considered to be an extremely precise and concise discipline, legal principles must be integrated and interpreted according to a specific legal system. The purpose of teaching Legal English is to prepare students to practice law and familiarize them with the terminology. This can be achieved through the use of legal texts which help students develop a real understanding of legal terms and subjects.

\section{The difficulties Legal English teachers face in multilevel classes}

Despite the difficulties Legal English teachers face in the class, these difficulties become even more 
prominent when then they have to deal with a large multilevel class. What is a large multilevel class? These classes are large ones because they contain many students within the class. There 25 or 30 students in my classes in the Faculty of Law where I teach Legal English. Their knowledge in General English is different, so they possess different levels of English and this is one of the major factors which make Legal English teaching even more challenging. These students possess different language acquisition abilities. They have different attitudes toward language and their learning styles change as well. These classes tend to be highly heterogeneous. In these classes students have different cultural and educational background and different personalities as well. Due to their level of General English and other factors, they have different expectations. They are also motivated in different ways. In these classes students have been arranged by age and no importance was given to their language ability. The students vary considerably in their language and literacy skills. They are in great need of personal attention and encouragement to make progress. Teaching in these classes is definitely more challenging and more interesting.

There are also many benefits in teaching Legal English in large multilevel classes. In these classes the teacher is given the opportunity to make use of different activities. Students can perform different tasks by being divided into groups. Students can work together on different legal topics. By working together students interact more with each other. In multilevel classes students have the opportunity to work with different partners. Students whose level of Legal English is advanced can work with students of lower levels. In these cases students with a lower level of knowledge get motivated by their peers because they think that if they work hard with persistence even they can become as good as their friends. Brainstorming is also very effective in these classes. Since the number of students is high, they have the opportunity to generate many ideas in a written and oral form. In this way students share plenty of ideas.
Diversity and variety characterize the classes. When we teach in these classes we often think how wonderful would be to teach only a small group of students. Anyway in these classes students are never bored, because there are always enough students for interaction. In this way they never get bored with each-other and in most of the cases they are willing to interact with new students. The large number increases the energy level of the class, the interest and the linguistic output of the entire group. In small classes students get bored with each other since they start to know the other students very well in a short period of time and then they lose enthusiasm and interest. There is a great variety of human resource in these classes. Students have many opinions, many different experiences and many styles of learning. This variety can be exploited by the teacher in creating interesting, meaningful and student-centered lectures. In these classes the students can learn as much from each other as they can learn from the teacher. It is very important to create the climate that encourages students to help one another or ask help from their peers. Cooperation works better than competition in multilevel classes. Cross-ability grouping allows the more able learners to improve their language skills by honing their ability of explaining, stating clearly and giving effective examples, while it provides the less able with considerable support. The teacher should try to be as effective as he/she can. This environment faces the teachers with many challenges. Some of the challenges are as following:

Different levels: These classes have students who possess different levels of General English. In this situation it becomes even more difficult to teach Legal English to students. That is why it is very important to conduct a needs' analysis at the beginning of the year. When the teacher is informed about the level of knowledge students have and about their weaknesses and strongest points, then it becomes easier for her to plan the classes ahead, to search for new sources, to apply different strategies. Also, students of lower levels need to focus on specific needs, 
while the best students need to discuss about specific problems or issues such as "The weaknesses and the strengths of Albanian Legal system".

Lack of time: Since the number of students in these classes is higher compared to smaller classes it is very important to manage time effectively. Creating or having a routine helps the teacher to manage time effectively and not wasting time by guiding students about new actions they have to perform in the class. Also, due to the large number of students there is not enough time to focus in the same way to the four skills which are listening, speaking, reading and writing. Since writing requires a lot of time and effort maybe the students can work with different writing assignments at home or maybe working in pairs in the class can help them practice writing in the class.

Some activities that can help students improve speaking in a multilevel Legal English class are:

- Competition;

- Moot courts or mock trials;

- Class debates;

- Presentations (3-5 minutes).

Some activities that can help students improve the skill of writing are:

- Free writing;

- Brainstorming;

- Paraphrasing;

- Writing essays on different topics;

- Summarizing;

- Case briefs.

Some activities that can help students improve the skill of speaking are:

- Guessing the meaning of the new words based on the context.

- Providing definitions for the unknown words;

- Open-ended questions;

- Dialogues;

- Debates.

Some activities that can help students improve the skill of reading are:

- Comprehension check;

- Match the words with their definitions;
- Fill in the gaps;

- Reading different cases regarding Human Rights from the EU Courts;

- European Convention of Human Rights.

Grammar: Should teachers practice grammar in these classes since it is an ESP class? Students have different knowledge in General English and in some of the cases it is necessary to deal with grammar. If students have problems or do not use the right tenses, then they won't be able to express themselves or their ideas won't be expressed clearly. In these cases the teacher may help students revise grammar issues, but in a legal context. So, in this way they can practice grammar and new legal terminology as well.

Class Management: This is another problem that teachers encounter in large multilevel classes (Hess [1]). When there are many students in the classroom, they are more inclined to make noise, to distract other students, to raise their voices. That is why class management is a really difficult task. How can it be achieved? It can be achieved by involving every student in the class in different assignments and in different work groups. We often feel like we are out of control or like we are losing the control in our class. Anyway good organization helps us to promote control. In some of the cases it is necessary to create a routine that students have to follow during the class in order to have a more effective class. Good organization helps students to know what is expected from them and to get on with the task quickly (Hess [1, 4]). Sometimes, we feel like we are trapped in the problems of management. Again having some work routine helps us to manage the class. If we realize that a routine isn't working or isn't as effective as we thought it would be, we should not hesitate to start having a new routine in the midterm. Routines are created to guide us and not to bind us. It is difficult to provide personal or individual learning styles. The teachers can use signals to get students' attention or to change tasks during the class.

Weakest students are left apart- Activating the quiet student is very difficult (Hess [1]). It is 
easier to let the students who are better than others participate and dominate the whole class. It is very important to find ways to engage even the other students who don't feel confident with their knowledge or who don't like to participate in different discussions. In some of the cases these students are afraid to express their own ideas because they don't feel comfortable and confident with their knowledge. Our job as language teachers is to help students gain competence in language and to provide support and encouragement that will raise their confidence and motivation. We must assure these students that what they think really matters to us more than the way they express themselves.

Losing students' attention- In these classes it is very easy to lose the attention of the students (Hess [1]). Attracting their attention is the greatest challenge. Facilities, visual aids, different images can help the teacher attract students' attention. Again variety is very important in these classes because a variety of techniques and activities can accommodate students of different levels. Variety is very important in provoking interest in large groups of students. In large classes interest is very important because in these classes if students lose their interests they are more inclined to either cause trouble or distraction to other students. How can you be an interesting teacher? Students' curiosity can be aroused by choosing different topics. Making meaningful questions enhances their critical thinking and generating ideas. Linking the topic with reality increases their interest as well. However interesting topic won't automatically generate appeal to them. The topic should be intertwined with different activities which have clear goals and motivating processes that guide students through involving tasks into thoughtful and insightful use of language.

Monitoring the groups / students- It looks like impossible to monitor all the students (Hess [1]). In this case assigning roles to students can be very helpful. They feel more responsible and aware of their mission. One of the students can be the time keeper, another one can collect the papers in cases of written assignments. Once roles are assigned to students, they feel like they are in charge of the whole class and they are motivated to do their best and motivated to encourage the other students to do their best as well.

Error correction - In these classes it becomes almost impossible to check and correct the errors of each student. That is why peer correction can be really helpful. Students in pairs or in groups can assess each others' tasks. It is a good idea to mix and mingle students of different levels together.

Collaboration means working together and cooperating. Through collaborative learning, students participate more. They learn how to compromise and how to encourage one another. In a large multilevel class the teacher can't be everywhere at the same time. Therefore, students should make use of other students' help as language resources. Sometimes giving students' responsibilities by assigning them roles is the best solution (Hess $[1,4]$ ). By having roles, students become more responsible and aware of their purpose by staying concentrated most of the time.

What are some tendencies of effective teachers? Some of the tendencies of effective teachers are as following (Westwood [3, 68]):

- Show enthusiasm;

- Well-managed classroom;

- Provide students with maximum opportunity to learn;

- Have high rather than low expectations of what students can achieve;

- Involve all students in the lesson;

- Use strategies to keep students motivated and productive;

- Present new material in a step -by- step process/manner;

- Use clear instructions and explanations;

- Use a variety of teaching styles, methods and resources;

- Monitor closely what students are doing throughout the lesson; 
- Pays attention to individual needs and re-teach when necessary;

- Provide frequent feedback to students;

- Use high rates of questioning to involve students and to check their understanding;

- Differentiate questions according to students' abilities.

\section{Conclusions}

The acquisition of English for Specific Purposes has become a necessity nowadays. Many people are eager to become successful in different fields. English has become a key component in helping them achieve professional and career development. Possessing good knowledge in General English isn't enough for ambitious people and students. The need of being good at English for Specific Purposes has become more prominent than ever before.

Law students face many challenges during the learning process of Legal English. They face difficulties understanding the content of the subject and they lack vocabulary to express their ideas. Some students have limited knowledge in General English. Teachers as well face many challenges while teaching Legal English. Teaching Legal English is a huge challenge for teachers who are not experts in law. Teachers face problems since they have to teach content in an area of study about which they have little knowledge. Team-teaching proves to be very helpful for ESP teachers. In this case the ESP teacher collaborates with a subject specialist. Legal English teachers can effectively cooperate with Law teachers.

Legal English is characterized by a special language in which are included legal terms of art, legal jargon, word which have a different meaning in General English and a different one in Legal English, words that are used in a peculiar context, lack of punctuation and the use of doublets and triplets.
In multilevel classes these challenges become even more prominent. Students possess different levels of General English and this is one of the major factors which make Legal English teaching even more challenging. These students possess different language acquisition abilities. They have different attitudes toward language and their learning styles change as well.

Some of the challenges that teachers face in multilevel classes are related to: different levels of students, lack of time, class management, the practice of grammar during the Legal English class, collaboration of students, error correction, losing students' attention, monitoring the students and the weakest students being left apart.

There are also many benefits in teaching Legal English in large multilevel classes. In these classes the teacher is given the opportunity to make use of different activities such as discussing, brainstorming, working in groups. Students can work with different partners. Diversity and variety dominate these classes. In these classes the students can learn as much from each other as they can learn from the teacher. The climate that encourages students to help one another or ask help from their peers helps the students and the teachers to achieve the objectives. Collaboration is the best way to learn in these classes. The teacher can engage students in many activities which aim to improve the skills of reading, writing, listening and speaking Legal English.

Finally, Legal English teachers can be effective in multilevel classes by showing enthusiasm, managing the classroom, involving all the students in the lesson, using a variety of teaching styles and methodologies, paying attention to individual needs, providing frequent feedback to students and motivating students to keep improving their knowledge. 


\section{References:}

1. Hess Natalie. “Teaching Large Multilevel Classes”, Oxford University Press, 2001.

2. Walenn Jeremy. "English for Law in Higher Education Studies, Teacher's Book", Garnet Publishing Ltd, 2009.

3. Westwood Peter. "Effective Teaching", Australian Journal of Teacher Education,-Vol. 21.- Issue 1, 1996.

4. Codruta Badea Elena. "Teaching Legal English as a Second Language”, Splaiul Uniri - No. 176. - Bucharest, $-832 \mathrm{p}$.

5. Tavakoli Mansoor, Nasri Najmeh, Rezazadeh Mohsen. "Applying strategies for dealing with lack of subject knowledge: Can language teachers be effective ESP teachers?” English for Specific Purposes World, ISSN1682-3257. URL:http://www.esp-world.info,- Issue 37.- Vol. 13. 2013.

6. John \& Dudley-Evans. "An experiment in team-teaching of overseas postgraduate students of transportation and plant biology", British Council 549,- P. 6-23.

7. Hutchinson Tom \& Waters Alan. "English for Specific Purposes: A learning-Centred Approach”, Cambridge University Press, 1987.

8. Gonzales M.U., Vyushkina E. G. "International cooperation in designing effective methods to prepare non-native EFL teachers for training and assessing legal English skills”, Georgetown Law Global Legal Skills Conference IV, June 4-6, Washington, DC, 2009.

9. MellinkoffDavid. “The language of law”,-P. 11-29.-Boston: Little Brown and Company, 1963.-P.386-406.

10. Haigh Rupert. "Legal English", - Routledge Cavendish, 2009.

11. Putman William. "Legal Analysis and Writing", 2 edition, Thomson Delmar Learning, 2003.

12. Saleh Qasim Al-Badwawi Halima. “The perceptions and Practices of First Year Students: Academic Writing at the Colleges of Applied Sciences in Oman”. The University of Leeds, 2011.

13. Delija Shpresa \& Buza Luljeta. "Legal English 1". - Tiranë, Doruntina, 2006. 